\title{
4.3 A STUDY OF SOME ASTRONOMICAL DATA IN MUSLIM CALENDAR
}

\author{
Chen Meidong \\ Institute for the History of Natural Science \\ Academia Sinica, Beijing, \\ China
}

The Muslim Calendar spread into China in 1385 where it was immediately translated into Chinese by the astronomer Yuan Tong and came into use. In 1477 , it was further translated by the astronomer Bei Lin and compiled into the "Qi Zheng Tui Bu", a work more or less the same in substance with the Muslim Calendar recorded in the "Ming Shi Li Zhi", both being works of the same source. They left for us the valuable data of the results of research of ancient Arabian astronomers.

On different occasions in the Muslim Calendar, values different with one another are used for the same kind of data. In that case, which of them are used for them are accurate values surveyed and calculated by people who originally worked out the Muslim Calendar? And how are these values calculated from data now available? Now let us take as an example the average daily degree of solar motion ( $V$ ) relative to the vernal equinox and give a brief illustration:

In "the day table", there are 3 different values for $V$ : The daily degree of motion 59'08" ( $\left.V_{1}=0^{0} .98555556\right) ; V_{2}=28^{\circ} 35^{\prime} 02^{\prime \prime} / 29=$ $0^{0} .98565134 /$ day; $V_{3}=29^{\circ} 34^{\prime} 10^{\prime \prime} / 30=0^{\circ} .98564815 /$ day. According to $V_{1}$, there are $28^{\circ} 34^{\prime} 52^{\prime \prime} / 29$ days and $29^{\circ} 34^{\prime} 00^{\prime \prime} / 30$ days.

Comparing with $V_{1}, V_{2}$ and $V_{3}$ are lower by $10 "$, which explains why $1^{\prime \prime}$ is added to each of the degrees of motion for the 10 dates in the table. This shows that in the minds of those who compiled the calendar, $V_{1}$ is a value on the low side, while $V_{2}$ and $V_{3}$ are better values after revision.

In "the month table", there are also two different values for $V$ : in the case of a common year $\left(V_{4}=348^{\circ} 55^{\prime} 09^{\prime \prime} / 354\right.$ days $=$

$0^{0} .98564736 /$ day $)$; in the case of a leap year $\left(V_{5}=349^{\circ} 54 \cdot 77^{\mathrm{N} / 355}\right.$ days $=0^{0} .98564710 /$ day). According to $V_{2}$ and $V_{3}$, the sun revolves $348^{\circ} 55^{\prime} 12^{\prime \prime}$ in a common year, and $349^{\circ} 54^{\prime} 20^{\prime \prime}$ in a leap year, which are $3 "$ higher than those recorded in the table. It can explain why 1 " is made less from each of the degree of motion per 3 months in the table. This shows that in the compiler's opinion, $V_{2}$ and $V_{3}$ are values on the higher side, while $V_{4}$ and $V_{5}$ are better values after further revision. 
It is known that in 30 lunar years there are 19 common years and 11 leap years with 10631 days in all. According to $V_{4}$ and $V_{5}$, the total degrees of solar motion in 30 lunar years are $348^{\circ} 55^{\prime} 09^{\prime \prime} \times 19+$ $349^{\circ} 54^{\prime} 17^{\prime \prime} \times 11=29 \times 360^{\circ}+38^{\circ} 24^{\prime} 58^{\prime \prime}$. But in "the 30 lunar years table", calculation is made with 30 lunar years moving $38^{\circ} 25^{\prime} 01^{\prime \prime}$, compared with which our calculated value is lower by $3^{\prime \prime}$. It is why 1 " is added to each of the degree of motion for the 3 years in the table. This shows that in the minds of those who prepared the calendar, the value more accurate than $V_{4}$ and $V_{5}$ should be $V_{6}=\left(29 \times 360^{\circ}+\right.$ $\left.38^{\circ} 25^{\prime} 01^{\prime \prime}\right) / 10631=0^{0} .98564735 /$ day .

If calculated according to $\mathrm{V}_{6}$, the solar motion of 840 lunar years should be $\left(29 \times 360^{\circ}+38^{\circ} 25^{\prime} 01^{\prime \prime}\right) \times 28=814 \times 360^{\circ}+355^{\circ} 40^{\prime} 28^{\prime \prime}$. But in "the 1440 lunar years table", calculation is made with 840 lunar years moving $160^{\circ} 05^{\prime} 33^{\prime \prime}$ - $164^{\circ} 25^{\prime} 19^{\prime \prime}=355^{\circ} 40^{\prime} 14^{\prime \prime}$, which is $14^{\prime \prime}$

less than in our calculation. It explains why 1 " is made less from each of the degree of motion for the 14 years in the table. This shows that in the mind of compilers, $V_{6}$ is a value slightly higher, and the real accurate value ought to be $V_{7}=\left[\left(29 \times 360^{\circ}+38^{0} 25^{\prime} 01^{\prime \prime}\right) \mathrm{x}\right.$ $28-14 "] / 28 \times 10631=0^{0} .985647333 /$ day.

In brief, tables such as "the day table", "the month table", "the 30 lunar years ${ }^{11}$ and "the 1440 lunar years" in the Muslim calendar are all worked out on the basis of the accurate value $V_{7}$, surveyed and calculated by calendar-makers. The various values from $V_{1}$ to $V_{6}$ are all approximate values of $V_{7}$, the only difference being their degree of approximation. This conclusion can be applied without exception to the following astronomical data (1) to (6) whose corresponding value of $\mathrm{V}_{7}$ can be obtained in a way similar to the one stated above.

1 The average daily degree of solar motion relative to the vernal equinox $V_{7}$ (length of the tropical year):

It is known that $v_{7}^{t}=0^{0} .985647333,360^{\circ} / \mathrm{V}_{7}^{\mathrm{t}}=$ $365^{\alpha} .2421997$, this is length of the tropical year. In comparison with the theoretical value for the year 622 and 1348 , their respective error is found to be $\Delta=$ $6^{5} \cdot 7\left(2^{\mathrm{s}} \cdot 7\right)$. The errors of the following astronomical data as against the theoretical values for the year 622 and 1348 are all expressed in this form. However, the error of the Huang Ji Calendar (604) and the Shou Shi Calendar (1281) is found to be $\Delta=196^{\mathrm{s}}$ and $23^{\mathrm{s}}$, these are far worse than that of the Muslim Calendar.

Most scholars in the past were inclined to act according to the Muslim Calendar with intercalary 31 days in 128 tropical years, and calculated the length of the tropical year as $365(31 / 128)=365^{\alpha} .2421875, \Delta=7^{s} .8\left(3^{s} .7\right)$, which is in fact less accurate than the value originally surveyed and calculated by the Arabian astronomers. The intercalary 31 days in 128 tropical years are approximate values of the intercalary 31 days in 127.9936 tropical years. 
2 The average daily degree of lunar motion relative to the star $V_{7}^{s}$ (length of the sidereal month):

$V_{7}^{s}=\left[\left(389 \times 360^{\circ}+38^{\circ} 15^{\prime}\right) \times 28+5^{\prime}\right) / 28 \times 10631=13^{\circ} .17639479$, $360^{\circ} / \mathrm{V}_{7}^{\mathrm{s}}=27^{\circ}=.3215858$, this is length of the sidereal month, $\Delta=6^{\mathrm{s}} \cdot 3\left(6^{\mathrm{s}} \cdot 5\right)$.

However, the error of the Huang Ji Calendar and the Shou Shi Calendar is found to be $\Delta=1^{\mathrm{s}} .3$ and $1^{\mathrm{s}} .0$, they are more accurate than the Muslim Calendar.

3 The average daily degree of lunar motion relative to the sun $\mathrm{V}_{7}^{\mathrm{m}}$ (length of the synodic month):

$V^{m}=\left[\left(719 \times 360^{\circ}+359^{\circ} 40^{\prime}\right) \times 28+8^{\prime}\right] / 28 \times 10361=$

$24^{\circ} .38149482,720^{\circ} / V_{7}^{m}=29^{d} .5305930$. This is length

of the synodic month, $\Delta=0^{5} \cdot 6\left(0^{s} .5\right)$. However, the

error of the Huang Ji Calendar and the Shou Shi Calendar is

found to be $\Delta=0^{5} .8$ and $0^{5} .5$, they are of an equal

level with Muslim Calendar.

Most scholars in the past were inclined to act according to the Muslim Calendar with the intercalary 11 days in 30 lunar years, and calculated the length of the synodic month as $(30 \times 354+11) / 30 \times 12=29^{\mathrm{d}} .5305556, \Delta=2^{\mathrm{s}} \cdot 7\left(2^{\mathrm{s}} .8\right)$. In fact, it is approximate values that are used for originator of Muslim Calendar.

4 The average daily degree of lunar motion relative to the apogee $V_{7}^{a}$ (length of the anomalistic month):

$\left.V_{7}^{a}=\left(385 \times 360^{\circ}+293^{\circ} 47^{\prime}\right) \times 28+5^{\prime}\right] / 28 \times 10631=$ $13^{\circ} .06497849,360^{\circ} / \mathrm{V}_{7}^{\mathrm{a}}=27^{\mathrm{d}} .5545804$, this is length of the anomalistic month, $\Delta=1^{\mathrm{s}} .4\left(2^{\mathrm{s}} .1\right)$. However, the error of the Huang $\mathrm{Ji}$ Calendar and the Shou Shi Calendar is found to be $\Delta=0^{5} .8$ and $3^{\mathrm{s}} .7$, the Muslim Calendar is worse in accuracy than the Huang $\mathrm{Ji}$ Calendar and a bit better than the Shou Shi Calendar.

5 The average daily minute of the regression of nodes of ecliptic and lunar orbit $V^{n}$ (length of the nodical month):

$V_{7}=\left(562^{0} 58^{\prime} \times 28\right)+12^{\prime} / 28 \times 10631=3^{\prime} .177351949$, $360^{\circ} /\left(V_{7}+V q\right)=27^{d} \cdot 2122200$. This is length of the nodical month, $\Delta=0^{\mathrm{s}} \cdot 4\left(0^{\mathrm{s}} \cdot 1\right)$. However, the error of the Huang $\mathrm{Ji}$ Calendar and the Shou Shi Calendar is found to be $\Delta=0 .{ }^{5} 6$ and $0 .{ }^{s} .5$, they are pretty much the same with Muslim Calendar. 
6 The average daily degree of motion of the planets relative to the sun $\left(V_{7}^{1}-V_{7}^{5}\right)$---the planet synodic period:

Saturn: $V_{7}^{1}=\left[\left(28 \times 360^{\circ}+42^{0} 16^{\prime}\right) \times 28+8^{\prime}\right] / 28 \times 10631=$ $0^{0} .952146686,360^{\circ} / V^{\frac{1}{7}}=378^{\mathrm{d}} .0930028, \Delta=95^{\mathrm{s}} .7$.

Jupiter: $V_{7}^{2}=\left[\left(26 \times 360^{\circ}+234^{\circ} 39^{\prime}\right) \times 28+11^{\prime}\right) / 28 \times 10631=$ $0^{0} .902516842,360^{\circ} / \mathrm{V}_{7}^{2}=398^{\mathrm{d}} .8845230, \Delta=41^{\mathrm{s}} .1$.

Mars: Vz $=\left[\left(13 \times 360^{9}+227^{0} 01^{\prime}\right) \times 28+10^{\prime}\right) / 28 \times 10631=$ $0^{0} .461576543,360^{\circ} / \mathrm{V}_{7}^{3}=779^{\mathrm{d}} .9356461, \Delta=38^{\mathrm{s}} .4$.

Venus: $V_{7}^{4}=\left[\left(18 \times 360^{\circ}+74^{\circ} 15^{\prime}\right) \times 28+12^{\prime}\right] / 28 \times 10631=$ $0 .{ }^{0} 616523106,360^{\circ} / V^{4}=583^{d} .9197207, \Delta=$ $143^{5} .0$.

Mercury: $\mathrm{V}_{7}^{5}=\left[\left(91 \times 360^{\circ}+267^{0} 44^{\prime}\right) \times 28-6^{\prime}\right] / 28 \times 10631=$ $3^{0} .10673782,360^{\circ} / V^{5}=115^{\mathrm{d}} .8771744, \Delta=26^{\mathrm{s}} .2$.

The error of synodic period of Saturn, Jupiter, Mars, Venus and Mercury in the $\mathrm{Da}$ Ye Calendar (607) is found to be: $144^{\mathrm{s}} .7,168^{\mathrm{s}} .9,909^{\mathrm{s}} .6,19^{\mathrm{s}} \cdot 3$ and $166^{\mathrm{s}} .9$, and the Shou Shi Calendar $25^{\mathrm{s}} .5,349^{\mathrm{s}} .6,612^{\mathrm{s}} .7$, $1622^{\mathrm{s}} \cdot 3$, and $127^{\mathrm{s}} \cdot 7$. In point of the overall level of accuracy of the planet's synodic period, the Muslim Calendar is far better than traditional Chinese calendars. Nevertheless, the latter have their own merits. For instance, in accuracy the Muslim Calendar is not as good as the $\mathrm{Da}$ Ye Calendar for Venus and the Shou Shi Calendar for Saturn.

7 The annual value of advance of the Sun's apogee and the aphelion of the planet.

According to Muslim Calendar, the advance of the Sun's apogee and the aphelion of planet in 840 lunar years should be all $12^{\circ} 36^{\prime} 55^{\prime \prime}$, their daily value $\mathrm{V}_{\alpha}=$ $12^{0} 36^{\prime} 55^{\prime \prime} / 28 \times 10631, v_{\alpha} x_{7}^{t}=60^{\prime \prime} .01$, this is annual (tropical year) value of advance of the Sun's apogee and the aphelion of Saturn, Jupiter, Mars, Venus, and Mercury, their error each ought to be $2 "$ and 10", 2", 6", 9" 4". Ancient traditional Chinese Calendar had no conception of the advance of sun's apogee so that it cannot be compared with the Muslim Calendar. As for the annual value of advance of aphelion of the planets, we must wait for appearance of the Da Yan Calendar (728) to give for the first time a quantitative description, but it is far backward in accuracy than the Muslim Calendar. When we come to the Shou Shi Calendar, their error each ought to be: 69", 53", 44", 2", $3^{\prime \prime}$. It is rather accurate for Venus and Mercury, but as a whole, it still lags behind the Muslim Calendar. 
8 The longitude of the Sun's apogee and the aphelion of Planet. According to Muslim Calendar, at the epoch (16.5 July 622) the longitude of the Sun's apogee and the aphelion of Saturn, Jupiter, Mars, Venus, Mercury should be each:

$$
\begin{aligned}
& W_{S u}=B_{1}+89^{\circ} 21^{\prime}=78^{\circ} 40^{\prime} 32^{\prime \prime}, \Delta=0^{\circ} .65 \\
& W_{S a}=B_{1}+254^{\circ} 48^{\prime}=244^{\circ} 07^{\prime} 32^{\prime \prime}, \Delta=2^{\circ} .08 \\
& W_{J}=B_{1}+180^{\circ} 08^{\prime}=169^{\circ} 27^{\prime} 32^{\prime \prime}, \Delta=2^{\circ} .88 \\
& W_{M a}=B_{1}+135^{\circ} 04^{\prime}=124^{\circ} 23^{\prime} 32^{\prime \prime}, \Delta=6^{\circ} .33 \\
& W_{V}=B_{1}+77^{\circ} 06^{\prime}=66^{\circ} 25^{\prime} 32^{\prime \prime}, \Delta=134^{\circ} .41 \\
& W_{M e}=B_{1}+216^{\circ} 17^{\prime}=205^{\circ} 36^{\prime} 32^{\prime \prime}, \Delta=30^{\circ} .47
\end{aligned}
$$

where

$$
B_{1}=360^{\circ}-10^{\circ} 40^{\prime} 28^{\prime \prime}=349^{\circ} 19^{\prime} 32^{\prime \prime}
$$

However, at its epoch the error of longitude of the Sun's apogee and the aphelion of planet in the Shou Shi Calendar is found to be each: $0^{\circ} .60$ and $0^{\circ} .73,2^{\circ} .80,5^{\circ} .84$, $136^{\circ} .72,1^{\circ} .16$. With the exception of Venus, the Muslim Calendar is inferior.

9 Mean longitude of Sun and planet.

According to Muslim Calendar, at the epoch ( 16.5 July 622) the mean longitude of Sun and planet should be each:

$$
\begin{array}{ll}
\overline{\mathrm{W}}_{\mathrm{Su}}=116^{\circ} 05^{\prime} 08^{\prime \prime}-01^{\prime} 04^{\prime \prime} & =116^{\circ} 04^{\prime} 04^{\prime \prime}, \Delta=1^{\circ} .14 \\
\overline{\mathrm{W}}_{\mathrm{Sa}}=\overline{\mathrm{W}}_{\mathrm{Su}}-359^{\circ} 18^{\prime} & =116^{\circ} 46^{\prime} 04^{\prime \prime}, \Delta=0^{\circ} .45 \\
\overline{\mathrm{W}}_{\mathrm{J}}=\overline{\mathrm{W}}_{\mathrm{Su}}-145^{\circ} 19^{\prime} & =330^{\circ} 45^{\prime} 04^{\prime \prime}, \Delta=0^{\circ} .90 \\
\overline{\mathrm{W}}_{\mathrm{Ma}}=\overline{\mathrm{W}}_{\mathrm{Su}}-264^{\circ} 06^{\prime} & =211^{\circ} 58^{\prime}, 04^{\prime \prime}, \Delta=1^{\circ} .13 \\
\overline{\mathrm{W}}_{\mathrm{V}}=\overline{\mathrm{W}}_{\mathrm{Su}}+45^{\circ} 29^{\prime} & =161^{\circ} 33^{\prime} 04^{\prime \prime}, \Delta=2^{\circ} .68 \\
\overline{\mathrm{W}}_{\mathrm{Me}}=\overline{\mathrm{W}}_{\mathrm{Su}}+85^{\circ} 34^{\prime} & =201^{\circ} 38^{\prime} 04^{\prime \prime}, \Delta=1^{\circ} .38
\end{array}
$$

However, at its epoch the error of mean longitude of Sun and Saturn, Jupiter, Mars, Venus, Mercury in the Shou Shi Calendar should be each: $0^{\circ} .99$ and $0^{0} .36,0^{0} .51,0^{0} .73,0^{0} .02,10^{\circ} .34$. With the exception of Mercury, the Muslim Calendar is inferior.

In summing up what is stated above, we might say that the accuracy of the length of the tropical year set by the Muslim Calendar is much 
higher than that set by traditional Chinese calendars. What is more is that the conception and value of advance of apogee of the Sun are lacking in the latter. Judging from the overall level of accuracy for determining the synodic period of planet and the value of advance of aphelion, the Muslim Calendar is also better than traditional Chinese calendars. But traditional Chinese calendars are more accurate than the Muslim Calendar in determining the value of the sidereal month. Judging from the overall level of accuracy for determining the mean longitude of Sun and planet and the longitude of Sun's apogee and aphelion of planet, the traditional Chinese Calendar is also better than Muslim Calendar. As for the accuracy in the determination of the value for the synodical month, the anomalistic month and the nodical month, traditional Chinese calendars and the Muslim Calendar are in equal level. All these show that both of them have originality and are all remarkable ancient astronomical works.

\author{
REFERENCES \\ Bei Lin, "Qi Zheng Tui Bu" ( 七政推少), 2, Commercial \\ Chen Meidong (1983). On the Determination of the Length of the Years \\ and the Months in Ancient China, Collected Works for the \\ History of Science and Technology, Shanghai Scientific and \\ Technical Press, Shanghai. \\ Chen Meidong (1985). Measurement and Calculation of Longitudes of \\ Planetary Perihelion and Their Values of Advance in \\ Ancient China, Studies in the History of Natural Sciences, \\ No.2, Beijing \\ History of Sui Dynasty ( $\frac{1}{6}$ ), 17, 88, Chine
Publishing House, Beijing, (1973). \\ History of Ming Dynasty ( 8 \& $R^{\prime}$ ), 37, 38, Chinese Book \\ Publishing House, Beijing, (1974). \\ History of Yuan Dynasty( $\left.\tau^{2}\right), 55$, Chinese Book Publishing \\ House, Beijing, (1976).
}

